\title{
Some Approaches to the Analysis of a Group of Repeated Measurements Experiment on Mahogany Tree with Heteroscedustic Model
}

\author{
Md. NASIRUl ISLAM ${ }^{1 *}$, AbU SyeEd Md. RiPOn ROUF ${ }^{1}$ AND M. MAZIBAR RAHMAN ${ }^{2}$ \\ ${ }^{1}$ Open School, Bangladesh Open University, Gazipur, Bangladesh \\ ${ }^{2}$ Department of Statistics, Jahangirnagar University, Savar, Dhaka, Bangladesh
}

Received 24 March 2004; received in revised form 16 November 2005; accepted 22 June 2006

\begin{abstract}
Combined analysis of a group of repeated measurements experiments could play an important role in both the causes either the variance might be known or unknown. Ordinarily the variances vary from experiment to experiment depending on places and environmental conditions due to great irreconcilable inherient causes. On the other hand the variances are obviously related as a functional form of the respective error variances in different places. Relying on the functional form some tests criterion are proposed for removing any resulting bias.
\end{abstract}

Key words: Repeated measurements experiments, divergency and convergency, percentage rotatability.

\section{INTRODUCTION}

The analysis of repeated measurements experiments is a powerful experimental test procedure in the field of agricultural, biological and clinical research (Rahman, 1989; Madsen, 1977; Lana \& Lubin, 1963). However, in all the cases they used in a single repeated measurement experiment. Rahman and Miah (1992) used combined analysis in more than one experimental design. They considered the variance-covariance structure among the different experiments are equal. Nevertheless, when the experiments are conducted in different places the variance and covariance matrix are not equal. In that case the analytical procedure is very much complicated. In this paper, an analytical procedure to overcome the problem through an example on Mahogany trees has been proposed.

\section{MATERIALS AND METHODS}

A repeated measurements experiment is that which has treatment structure, at least one treatment factor is not randomly assigned having more than one different size of experimental units. The required repeated measurements model can be expressed as-

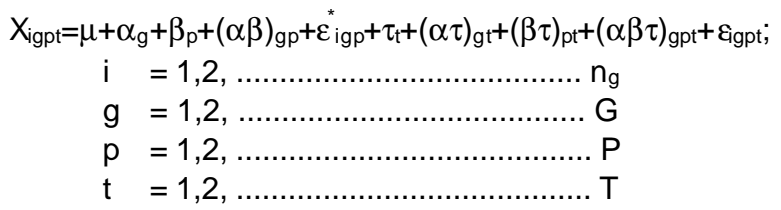

* Corresponding author: Associate Professor, Open School, BOU. E-mail: islamn@bou.edu.bd

(C) 2006, School of Agriculture and Rural Development, Bangladesh Open University. All rights reserved. 
Md. Nasirul Islam et al.

Where,

$\mathrm{X}_{\mathrm{igpt}}=$ the responses of the ith individual in the gth group on pth place at the th occasion.

$\begin{array}{lll}\mu & = & \text { the general mean } \\ \alpha_{\mathrm{g}} & = & \text { the effect of the gth group }\end{array}$

$\beta_{\mathrm{p}}=$ the effect of the pth place

$(\alpha \beta)_{\mathrm{gp}}=$ the interaction effect between the gth group at the pth place

$\varepsilon_{\text {igp }}=$ the effect associated with the ith subject in the gth group on the pth place

$\tau_{t} \quad=$ the effect of the th occasion

$(\alpha \tau)_{\mathrm{gt}}=$ the interaction effect between the gth group at the th occasion

$(\beta \tau)_{\mathrm{pt}}=$ the interaction effect between the pth place at the th occasion.

$(\alpha \beta \tau)_{\mathrm{gpt}}=$ the interaction effect among the gth group in the pth place at the th occasion

Egpt $=$ the error associated with the ith subject in the gth group on the pth place at

\section{Assumption} the th occasion.

Under the following assumptions the analysis of variance is given in Table 1.

1. $\varepsilon_{\text {igp }}^{*} \sim N\left(0, \sigma_{\varepsilon^{*}}^{2}\right)$

2. $\varepsilon_{\text {ggpt }} \sim \mathrm{N}\left(0, \mathrm{~s}_{\mathrm{e}}^{2}\right)$

3. both are independent

4. all the variances in the different places are equal i.e.

$\sigma_{\varepsilon^{*}}^{2^{(p)}}=\sigma_{\varepsilon^{*}}^{2^{(\mathrm{t})}}=\ldots \ldots . . .=\sigma_{\varepsilon^{*}}^{2^{(\mathrm{p})}}=\sigma_{\varepsilon^{*}}^{2^{(\mathrm{p})}} ; \mathrm{t}=1,2, \ldots \ldots \ldots . \mathrm{p}$

Table 1. ANOVA

\begin{tabular}{|c|c|c|}
\hline $\begin{array}{l}\text { Source of } \\
\text { variation }\end{array}$ & $\begin{array}{l}\text { Degrees of } \\
\text { freedom }\end{array}$ & EMS \\
\hline Group & G-1 & $\mathrm{s}_{\mathrm{e}}^{2}+\frac{\mathrm{TP}}{(\mathrm{G}-1)} \mathrm{Sn}_{\mathrm{g}}\left(\mathrm{a}_{\mathrm{g}}-\overline{\mathrm{a}} \cdot\right)^{2}$ \\
\hline Place & P-1 & $\mathrm{s}_{\mathrm{e}}^{2}+\frac{\mathrm{GT}}{(\mathrm{P}-1)} \mathrm{S}\left(\beta_{\mathrm{p}}-\overline{\beta_{.}}\right)^{2}$ \\
\hline GroupxPlace & $(G-1)(P-1)$ & $\mathrm{s}_{\mathrm{e}}^{2}+\frac{\mathrm{N}}{(\mathrm{G}-1)(\mathrm{T}-1)} \mathrm{SS}\left\{(\mathrm{a} \beta)_{\mathrm{gp}}-(\mathrm{a} \bar{\beta})_{\mathrm{p}}-(\overline{\mathrm{a} \beta})_{\mathrm{g} .}+(\overline{\mathrm{a} \beta}) . .\right\}^{2}$ \\
\hline Error-I & $P(N-G)$ & $\sigma_{\varepsilon}^{2}+\sigma_{\varepsilon^{*}}^{2}$ \\
\hline Occasion & $(\mathrm{T}-1)$ & $\mathrm{S}_{\mathrm{e}}^{2}+\frac{\mathrm{NP}}{(\mathrm{T}-1)} \mathrm{S}\left(\mathrm{t}_{\mathrm{t}}-\overline{\mathrm{t}} .\right)^{2}$ \\
\hline Group $\times$ Occasion & $(\mathrm{G}-1)(\mathrm{T}-1)$ & $\sigma_{\varepsilon}^{2}+\frac{P}{(G-1)(T-1)} \Sigma \Sigma n_{g}\left\{(\alpha \tau)_{g t}-(\alpha \bar{\tau})_{. t}-(\overline{\alpha \tau})_{t .}+(\overline{\alpha \tau})_{. .}\right\}^{2}$ \\
\hline Place×Occasion & $(P-1)(T-1)$ & $\left.\sigma_{\varepsilon}^{2}+\frac{\mathrm{G}}{(\mathrm{P}-1)(\mathrm{T}-1)} \Sigma \Sigma\{\beta \tau)_{\mathrm{pt}}-(\overline{\beta \tau})_{. \mathrm{t}}-(\bar{\beta} \tau)_{\mathrm{p} .}+(\overline{\beta \tau})_{. .}\right\}^{2}$ \\
\hline Grop $\times$ Place $\times$ Oocasion & $(G-1)(P-1)(T-1)$ & $\mathrm{s}_{\mathrm{e}}^{2}+\frac{1}{(\mathrm{P}-1)(\mathrm{T}-1)(\mathrm{G}-1)} \mathrm{SSS}(\mathrm{a} \beta \mathrm{t})_{\mathrm{gpt}}^{2}$ \\
\hline Error-II & $\mathrm{GT}(\mathrm{N}-\mathrm{G})$ & $\mathrm{S}_{\mathrm{e}}^{2}$ \\
\hline
\end{tabular}


The following hypothesis are to be tested:
1. $\mathrm{H}_{0}$ (group)
: $\alpha_{1}=\alpha_{2}=$ $=\alpha_{g}$ i.e. the group effects are equal
2. $\mathrm{H}_{0}$ (place)
: $\beta_{1}=\beta_{2}=$ $=\beta_{p}$ i.e. the place effects are equal
3. $\mathrm{H}_{0}$ (groupxplace)
: The group $\times$ place interaction effects are nil
4. $\mathrm{H}_{0}$ (occasion)
5. $\mathrm{H}_{0}$ (groupxoccasion)
$: \tau_{1}=\tau_{2}=$ $=\tau_{t}$ i.e. the occasion effects are equal
6. $\mathrm{H}_{0}$ (placexoccasion)
: The groupxoccasion interaction effects are nil
7. $\mathrm{H}_{0}$ (groupxplacexoccasion)
: The placexoccasion interaction effects are nil
: The groupxplacexoccasion interaction effects are nil

The above hypotheses about the main effects and the interaction effects can be tested by using Fstatistic with respective degrees of freedom.

Previously the analysis considered the variances among different places are equal, which is a reasonable assumption in any case. One method for analysing data when variances are unequal simply to ignore the fact that they are unequal and calculate the same statistics. Surprisingly these tests are quite good, in particular if the variances in different places are all equal or almost equal.

If the variances in different places are not equal the usual test statistic is not valid.

Moreover, the variance structure would be a function with the respective error variances in different places, then the functional form are as follows:

1. $\Sigma^{*}$ (variance structure $)=\varphi\left(\Sigma_{\mathrm{p}}^{*}\right)=\mathrm{a}_{0}+\sum_{\mathrm{p}=1}^{\mathrm{p}} \mathrm{a}_{\mathrm{p}} \Sigma_{\mathrm{p}}^{*}$; linear functional form.

$\Sigma^{\star}=$ Combined variance co-variance matrix

2. $\Sigma^{*}$ (variance structure $)=\varphi\left(\mathrm{S}_{\mathrm{p}}^{*}\right)=\mathrm{a}_{0}+\sum_{\mathrm{p}=1}^{\mathrm{p}} \mathrm{a}_{\mathrm{pp}} \mathrm{S}_{\mathrm{p}^{\prime}}^{* 2}+\underset{\mathrm{p}}{\mathrm{S}} \underset{\mathrm{p}^{\prime}}{\mathrm{S}} \mathrm{a}_{\mathrm{pp}} \mathrm{S}_{\mathrm{p}}^{*} \mathrm{~S}_{\mathrm{p}^{\prime}}^{*} ; \mathrm{p} \neq \mathrm{p}^{\prime}$ quadratic functional form

3. $\Sigma^{*}($ variance structure $)=\varphi\left(\Sigma_{\mathrm{p}}^{*}\right)=\sum_{\mathrm{p}=1}^{\mathrm{P}} \mathrm{c}_{\mathrm{p}} \Sigma_{\mathrm{p}}^{*} ;$ linear contrast

4. $\quad \mathrm{P}_{\mathrm{p} \rightarrow \infty} \int_{1}^{\mathrm{p}} \varphi\left(\mathrm{S}_{\mathrm{p}}^{*}\right) \mathrm{d} \mathrm{S}_{\mathrm{p}}^{*}=\mathrm{P}_{\mathrm{limt}} \int_{\mathrm{p} \rightarrow \infty}^{\mathrm{p}} \varphi\left(\mathrm{S}_{\mathrm{p}}^{*}\right)$; which implies either divergency or convergency.

Some test criterions are Suggested for testing

$$
H_{0}: \sigma_{\varepsilon^{*}}^{2^{(p)}}=\sigma_{\varepsilon^{*}}^{2^{(p)}}=\ldots \ldots . .=\sigma_{\varepsilon^{*}}^{2^{(p)}} ; p=1,2, \ldots \ldots \ldots . P
$$

\section{Test Procedure}

1. If the corresponding mean sum of square is substantially large than the mean square error in different places then the linear equation does not represent the true response surface (Islam, 1992) i.e. the hypotheses is not accepted.

2. Islam (1992) showed that if the percentage rotatability is equal to or about to equal

$\varphi n(D)=100 \sqrt{\sum_{p=1}^{P} \Sigma_{0 p}^{* 2}}=100$; then the test is not significant i.e. the null hypotheses is accepted. 
3. Consider the null hypotheses

$$
\begin{aligned}
& \mathrm{p} \\
& \mathrm{H}_{\mathrm{o}}(\text { place })=\sum \mathrm{c}_{\mathrm{p}} \Sigma_{\mathrm{p}}^{*}=\Sigma_{\mathrm{p}}^{*}=0 \\
& \mathrm{p}=1 \\
& \mathrm{p} \\
& \mathrm{H}_{\mathrm{a}}(\text { place })=\Sigma \quad \mathrm{c}_{\mathrm{p}} \Sigma_{\mathrm{p}}^{*} \neq 0 \\
& \mathrm{p}=1
\end{aligned}
$$

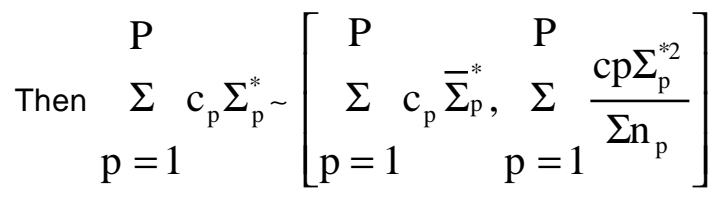

where $n_{p}$ number of sample in different places

Then the test statistic

$$
\mathrm{Z}=\frac{\mathrm{P}=1 \frac{\mathrm{P}}{\sum \mathrm{c}_{\mathrm{p}} \bar{\Sigma}_{\mathrm{p}}^{*}-\sum \mathrm{c}_{\mathrm{p}}{ }_{\mathrm{p}}^{*}}}{\sqrt{\sum_{\mathrm{p}=1}^{\mathrm{P} \frac{\mathrm{c}_{\mathrm{p}} \Sigma_{\mathrm{p}}^{* 2}}{\sum \mathrm{n}_{\mathrm{p}}}}}} \sim \mathrm{N}(0,1)
$$

the Z statistic follows standardized normal distribution.

4. If the number of places $N>15$, then the test statistic would be followed:

$$
\mathrm{P}_{\operatorname{limt}_{\mathrm{p} \rightarrow \infty}} \int_{1}^{\mathrm{p}} \varphi\left(\Sigma_{\mathrm{p}}^{*}\right) \mathrm{d} \Sigma_{\mathrm{p}}^{*}=1=\mathrm{P}_{\mathrm{p} \rightarrow \infty} \int_{\mathrm{p}=1}^{\mathrm{P}} \varphi\left(\mathrm{S}_{\mathrm{p}}^{*}\right) \text {; indicates null hypothesis is accepted. }
$$

\section{Numerical example}

The data were derived from a group of experiments on Mahogany (switania macrophylla) trees conducted in different stations of Jahangirnagar University, Savar, Dhaka. The different pH values of the soil in which the trees grown are 5.4, 5.6 and 5.8. The land was prepared well and planted the "Mahogany" trees at the depth of 15 to $16 \mathrm{~cm}$. with a plant to plant spacing $70 \mathrm{~cm}$. Five trees were randomly assigned to each fertilizer in each group of different places. The time periods of the experiments were $20^{\text {th }}$ November 1993 to $19^{\text {th }}$ July 1994. The height of the trees were measured in every two months interval and were recorded in $\mathrm{cm}$. Thus $\mathrm{G}=3, T=3, P=5, \mathrm{O}=5$. [ $\mathrm{G}=\mathrm{group}$, $\mathrm{T}=$ Fertilizer, $\mathrm{P}=$ place, $\mathrm{O}=$ Occasion].

The objective of the experiments was to study the effects of a level of plantation in combination with 3 levels of Nitrogen on the growth of Mahogany. The analysis techniques would be followed by Repeated Measurements experimental Design.

The error variance of the three experiments were observed as $0.06716,0.17479$ and 0.34592 in different places. These error variances were heterogeneous as was observed. But suggested test statistic (I, II, III, IV) indicated that the null hypotheses were accepted. 
Thus, the usual analysis of variance is valid. The analysis of variance Table 2 is given below.

Table 2. ANOVA

\begin{tabular}{lcccc}
\hline \multicolumn{1}{c}{ S.V. } & D.f. & M.S. & F.ratio & Power \\
\hline \hline Place & 2 & 43.8867 & 7.5767 & 0.000313 \\
Fertilizer & 2 & 2.4224 & 0.4182 & 0.3389 \\
Place \& Fertilizer & 4 & 0.2758 & 0.0426 & 0.50278 \\
Error-1 & 12 & 5.7923 & - & - \\
Occasion & 4 & 238.5279 & 26.2459 & 0.000216 \\
Place \& Occasion & 8 & 0.1043 & 0.01147 & 0.82395 \\
Fertilizer \& Occasion & 8 & 9.8092 & 1.0793 & 0.09258 \\
Place \& Fertilizer \& Occasion & 16 & 0.01136 & 0.001249 & 0.8729 \\
Error-2 & 48 & 9.08817 & - & - \\
\hline
\end{tabular}

Table 2 showed that the place and occasion effects are highly significant. But the fertilizer effect, place and fertilizer interaction effect, place and occasion interaction effect, place and fertilizer and occasion interaction effect are insignificant. The fertilizer and occasion interaction effect is insignificant. From the analytical results, the place and occasion effects are highly significant i.e. significant variation of growth of the plant over the time and the places are present in the experiment.

\section{CONCLUSION}

Designed field experiments on the effect of inorganic fertilizer were performed on the planted seedlings of Mahogany, the most widely used plantation forestry species in Bangladesh. Therefore, it is very important to outline an experimental procedure to accomodate all of the plantation at a time. This experiment is very helpful for this purpose.

\section{LITERATURE CITED}

Islam, M. N. 1992. Analysis of repeated measurements experiments. Unpublished [MPhil Dissertation], Jahangirnagar University, Savar, Dhaka.

Lana, R. E. and Lubin, A. 1963. The effect of correlation on the repeated measures design. Education and Psychological Measurements 23, 729-739.

Madsen, K. S. 1977. A growth curve model for studies in morophomatrics. Biometrics 33, 659-669.

Rahman, M. M. and Miah, A. B. M. 1992. Combined analysis of a group of repeated measurements experiments with heteroscedustics model. Journal of Statistical Studies 12, 19-26.

Rahman, M. M. 1989. Comparison of methods for the analysis of repeated measurements experiments. Unpublished [PhD Dissertation], Aberdeen University, UK. 